\title{
Heuristics and Recommendations for the Design of Mobile Serious Games for Older Adults
}

\author{
Mônica da Consolação Machado, \\ Ronan Loschi Rodrigues Ferreira ${ }^{(D)},{ }^{2,3}$ and Lucila Ishitani ${ }^{2}{ }^{2}$ \\ ${ }^{1}$ Institute of Exact Sciences, University Center Newton Paiva, Belo Horizonte, Brazil \\ ${ }^{2}$ Department of Computer Science, Pontifical Catholic University of Minas Gerais, Belo Horizonte, Brazil \\ ${ }^{3}$ Department of Engineering, College Santa Rita-FASAR, Conselheiro Lafaiete, Brazil \\ Correspondence should be addressed to Lucila Ishitani; lucila@pucminas.br
}

Received 31 January 2018; Revised 30 May 2018; Accepted 6 June 2018; Published 2 July 2018

Academic Editor: Michael J. Katchabaw

Copyright (C) 2018 Mônica da Consolação Machado et al. This is an open access article distributed under the Creative Commons Attribution License, which permits unrestricted use, distribution, and reproduction in any medium, provided the original work is properly cited.

\begin{abstract}
As people get older, their physical and cognitive functions decline. Meeting these needs is an important goal to be reached, to propose activities that may contribute to a better quality of life, including leisure and learning. As such, this paper aims to present a set of heuristics and recommendations for the design of mobile serious games for older adults. To elaborate these heuristics and recommendations, we conducted two studies with older people. In the first study, we invited people aged 60 or more to evaluate mobile games, intending to collect data that could help us to adapt the heuristics that were already published to the public of this research. In the period between the two studies, we developed a serious mobile game (Labuta Batuta) that met the set of adapted heuristics. In the second study, we invited another group of older people, aged 45 or over, to qualitatively evaluate Labuta Batuta, in order to develop a Grounded Theory about the desirable characteristics for the design of serious mobile games for older adults. Besides a Grounded Theory, the second study allowed the identification of nine requirements to be considered when designing the mechanics of mobile games for older adults.
\end{abstract}

\section{Introduction}

In the last decades, the demand for the so-called "adult games" has grown, due to the ageing of the population [1].

During the ageing process, human being undergoes physical, psychic, and cognitive restrictions, facing new needs and expectations [1-3]. As life expectancy increases, it becomes necessary to offer more options for older adults, including learning and leisure.

Keeping healthy is an indicator of functional independence and longevity. The use of digital games helps to reduce disability and depression and to improve reaction times, balance, and mobility of older adults $[4,5]$. Ijsselsteijn et al. [2] state that digital games enhance the self-esteem and mental stimulation of the elderly. Many authors, as [6-8], emphasise that digital games can help older adults in terms of entertainment, relaxation, socialization, mental challenges, and physical fitness, improving the quality of the ageing process.

In order to enjoy all the benefits mentioned, digital games must be suitable for older adults, thus providing them a better life, with more health, fun, and social interaction.

With the technologies available today, especially mobile devices such as smartphones, we need to rethink ways to meet the needs and expectations of older adults. A game designer must know how to create enjoyable virtual experiences [9]. Observing the difficulties and restrictions imposed by age, it is necessary to pay special attention to the development of digital games aimed at older adults, especially regarding gameplay.

Gameplay covers possible actions and reactions generated by the game and the player, the controls, the interaction between players, the role of the characters in the game, and the mechanics of the game. 
There are, in the literature, heuristics and recommendations for the evaluation and design of gameplay. However, to date, there are few publications regarding older adults. In addition, many publications address health and cognitive impairments. So, following a different line of research, this work aimed to propose a set of heuristics and recommendations for the evaluation and design of educational games for older adults, focusing gameplay.

It was carried on with two main studies. In the first study, we investigated the validity of the existing heuristics for the evaluation of gameplay, concerning older adults. In the second study, we investigated the validity of Schell's lenses for the scope of this work. Schell [9] states that a good project comes from many possible perspectives and refers to these as lenses, by understanding that each lens is a different way of seeing the project. Each lens is specified by a set of questions about the project, which must be answered by the designer. While studying the lenses of game mechanics proposed by [9], we identified a gap, because they do not guarantee the designers will consider the educational needs of the older player.

Among the results achieved are the identification of new heuristics, nine new requirements or design lenses, and the proposal of a Grounded Theory that contributes to the design of mobile serious games for older adults.

This paper is organized as follows. Section 2 presents the background of this work and some related work. Section 3 presents the method we adopted. Sections 4 and 6 present the method, participants, materials, and results of the first and second studies, respectively. Section 5 describes the main characteristics of "Labuta Batuta", the game developed for the second study. Section 7 briefly discusses the results and Section 8 presents our main conclusions and also suggestions for future work.

\section{Background}

In the following subsections, we present previous work that supported this study, concerning human development in adulthood, digital games, and gameplay.

\subsection{Human Development in Adulthood. The human ageing} process causes physical, psychological, and cognitive decline.

The best known impairments of older people are those related to vision, which includes presbyopia, macular degeneration, glaucoma, cataract, reduced field of vision, reduced color, depth and contrast perception, decreased adjustment to the dark, and limited perception of small details $[1-3,10]$.

During the ageing process, cognitive limitations also occur. So, loss of memory, attention, association, perception, and reasoning must be considered in the development of digital games for older adults [11].

Other frequent impairments are related to reduction in hearing, increase of response time, motor difficulties [1, 3], and also cognitive constraints such as $[1,3,12]$ : reduced attention to details, reduced short-term memory, difficulty to perform new activities or old activities in a new way; reduced spatial cognition, or the ability to mentally manipulate images and patterns; and inability to remember the goals of a task to be performed. These impairments can be caused by diseases such as Alzheimer's disease but also by the natural ageing process.

According to Papalia et al. [13], people approaching retirement often wish to expand their minds and their skills to make a more productive and interesting use of leisure. Some adults simply enjoy learning and want to continue learning throughout life. Then, learning activities, work, and leisure should be available for people of all ages. This possibility can help the elderly to slow the impact of ageing on their physical and cognitive abilities, which often determines their emotional state.

In this context, digital games can contribute to the improvement of the ageing process, since they can be used as a means to soften the restrictions due to the age, such as cognitive, motor, perceptive, and psychosocial aspects of people [14-16]. Nguyen et al. [17] stated that, in addition to entertainment, serious games may have beneficial therapeutic effects for older people as they may improve their health and well-being. The authors carried out a Systematic Literature Review (SLR) focusing on the physical, cognitive, and social effects that serious games can provide for the elderly. The SLR results showed that $75 \%$ of the articles found confirm positive impacts of serious games for the elderly. In this line of research, Nouchi et al. [18] investigated the impact of the Brain Age game on cognitive functions of the elderly. The results showed that the elderly may improve their executive functions and their processing speed when playing Brain Age for 4 weeks.

2.2. Digital Games. Digital games can offer older users new and exciting forms of entertainment as well as stimulate various mental abilities. Koster [19] stated that games are "concentrated chunks ready for our brains to chew on. Since they are abstracted and iconic, they are readily absorbed. Since they are formal systems, they exclude distracting extra details". Because of these characteristics, "games serve as very fundamental and powerful learning tools" [19].

According to Savi and Ulbricht [20], digital games can provide benefits to the teaching and learning process; among them are motivating effect; development of cognitive abilities; learning by discovery; socialization; and motor coordination exercises.

Games whose main objective goes beyond pure entertainment are called serious games. Their main purpose is to convey a message, to teach a lesson, or to offer an experience [21]. These games should provide the challenge and allow players to develop their skills and learn new things that can be applied to the real world, while still being fun and attractive [22].

Older adults have interests and expectations regarding the use of digital games, which include not only fun and distraction but also learning and the expectation of keeping up to date [23]. That is why serious or educational games can attract their interest.

When designing games that meet the interests and expectations of older adults, it is important to consider the cultural characteristics of this audience, given that these characteristics vary for different groups of people and that 
people identify with the context in which they feel well [24, 25]. In order to develop digital educational games for older adults, it is necessary to take into account a low cost so that they can have access to the game, since many are retired and do not have much money to spend $[6,26]$.

One of the most important requirements for the development of games projects for older adults is the possibility of offering them the type of content they will enjoy and get involved, even if this requirement is not so obvious and easy to be specified [2]. Digital games design must also consider the knowledge and wisdom that improve with time, the diversity of experiences, and changes in the social and societal roles that come with age.

Older adults are more resistant and afraid to learn new things than young people. For example, they fear making mistakes, they need to know the usefulness of learning, they fear new methods, and they let mistakes decrease their selfesteem. However, because they have more experience and like to help each other, they can also be self-confident and motivated in relation to learning, although they need more time and practice, especially when new learning conflicts with prior knowledge. Thus, they "need guidance, not grades" [27] as a form of evaluation.

GameFlow is a scale that can be used to measure the player's skill and it is composed of 8 elements: concentration, challenge, skills, control, clear goals, feedback, immersion, and social interaction [28]. However, the scale GameFlow does not adequately describe the increase in knowledge. Based on the scale GameFlow, another scale was created to evaluate the improvement of knowledge: EGameFlow. This scale can be used as a reference for an educational game project [29].

Currently, mobile games have a large market share among mobile applications as there is a steady increase in the number of users using smartphones and other mobile devices. Statistics show that mobile games represent about 70 to $80 \%$ of downloads [4]. According to Chu Yew Yee et al. [7], the growing use of mobile phones by older adults makes mobile games for the elderly a promising niche for game developers, despite the small size of the device screens.

2.3. Gameplay. According to Mello and Perani [30], gameplay is the result of the union of three characteristics that are usually associated with games: rules as an internal element; the pursuit of goals by the players, performed through a sequence of tasks given to them; and the skill and experience of the players.

Gameplay includes "the problems and challenges a player must face to try to win the game" [31]; that is, it is the process by which a player reaches the goal of the game.

Gameplay incorporates the game mechanics which consist of rules that define the functioning of the game universe, the core of the game, and the interaction of the player with the game and with other players. Gameplay occurs when the player interacts with the mechanics of the game and possibly with other players [32].

Garris et al. [33] state that gameplay "can lead to certain user judgments or reactions such as increased interest,
TABLE 1: Items and lenses of game mechanics.

\begin{tabular}{lc}
\hline Items of game mechanics & Lenses concerning the items \\
\hline 1- Space & 21 - Functional Space \\
\hline 2- Objects, attributes and states & 22 - Dynamic State \\
\hline 3- Actions & 23 - Emergence and 24 - Action \\
\hline 4- Rules & 25 - Goals e 26 - Rules \\
\hline 5- Skill & 27 - Skill \\
\hline 6- Chance & 28 - Expected Value and 29- \\
& Chance \\
\hline
\end{tabular}

enjoyment, involvement, or confidence". These reactions encourage players to persist more and keep playing.

2.3.1. Game Mechanics. For the game design, Schell [9] proposed a hundred of lenses, which are small sets of questions to be answered by the designer. The seventh lens focuses on the elemental tetrad, composed of the following elements: aesthetics, mechanics, story, and technology. This lens allows the designer to consider each element separately and then all together.

For this research, we considered separately the element of game mechanics. According to Schell [9], "game mechanics are the core of what a game truly is. They are the interactions and relationships that remain when all of the aesthetics, technology, and story are stripped away". Game mechanics are composed of six main items which are related to nine lenses, as can be seen in Table 1 .

Besides the nine lenses directly linked to the six items of the game mechanics, there are 23 other lenses that help to achieve game balance [9]. According to Schell [9], "balancing a game is nothing more than adjusting the elements of the game until they deliver the experience you want", examining the game carefully.

2.4. Heuristics for Gameplay Evaluation. Nielsen [34] called "heuristics" his 10 general principles for interaction design "because they are broad rules of thumb and not specific usability guidelines". Desurvire et al. [35] provided a definition of heuristics as "design guidelines which serve as a useful evaluation tool for both product designers and usability professionals".

There are many sets of heuristics to evaluate gameplay. In this study, we used a set of heuristics that we have compiled from a literature review.

Federoff [31] identified heuristics for gameplay evaluation through literature review. In order to evaluate the heuristics found, a field research was carried out with designers of a game developer company. Data collection was performed through observations and interviews with employees of the company. After analysing the results obtained from the comparison of the field research data with the heuristics found in the literature review, new heuristics were proposed.

Desurvire et al. [35] proposed the Heuristic Evaluation for Playability (HEP). It was based on literature and reviews from gameplay experts and game designers. HEP is subdivided into gameplay, game story, mechanics, and usability. 


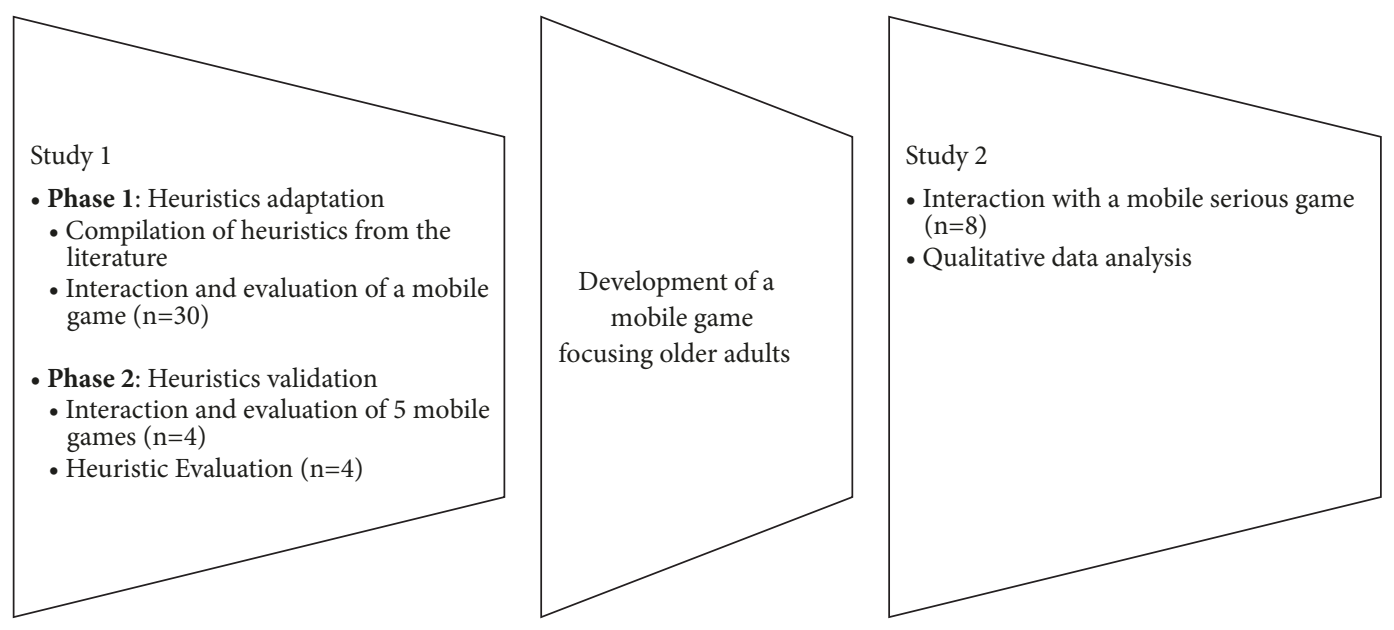

FIgURE 1: Research activities.

It consists of 43 heuristics, of which 16 are heuristics for gameplay evaluation. The heuristics were validated by means of a comparative study between the results of a heuristic evaluation and a user test. The results indicated that using the heuristics allowed to find gameplay problems in the game prototype. The total number of problems identified from the use of HEP was greater than the number of problems pointed out by the user test. According to the authors, HEP is useful in the initial project of the game, because it makes possible to think about the project from the point of view of the user, "avoiding expensive design problems".

Korhonen and Koivisto [32] stated that it is very important for the player to be in control, as it is the player's responsibility to decide what to do or how to do it. They also point out that games are more enjoyable and pleasant when they provide players with satisfying challenges. The authors proposed and validated Playability Heuristics for Mobile Games (PHMG), organized in three main modules: gameplay, mobility, and usability. PHMG consists of 29 heuristics for mobile game evaluation, of which 14 are gameplay-related. "A modular structure suggests that it is possible to use each of these modules separately and evaluate the game against one module at a time" [32]. They also reported that these heuristics are very general and can be applied to any game, regardless of the platform on which the game is played. The proposed heuristics were validated in evaluations of five games of different styles. 64 gameplay problems were found in these games. The results of this work confirm the importance of using gameplay heuristics to identify game design errors.

Desurvire and Wiberg [36] reported in their study that there "are many methodologies for analysing productivity software including Usability Testing and Heuristic Evaluation". The main focus of productivity software is the creation of an easy-to-use interface, helping users to execute tasks, which is the purpose of applications. Concerning games, however, the goals include providing an immersive, fun, and challenging environment. Several times a good pace of challenge makes it worth playing a game. Due to these differences and peculiarities of the games it is important to have a set of design principles. In this way, the authors carried out a research aiming to adapting the usability principles that exist to the design of games. Among the principles gathered and identified, 22 were related to gameplay. It is important to note that these principles were not related to the elderly, reinforcing the need for specific guidelines for games aimed at older adults, so that the pace and challenge are appropriate for the target audience, and the elderly can have a positive experience.

Korhonen et al. [37] report that in their work they used an expert evaluation method, although this method is not widely adopted for game evaluation. For the effectiveness of the method, heuristics should take into account the characteristics of games. Besides being applicable to games, the expert evaluation method is not too time-consuming or labor-intensive to be carried out. In their work, they used Heuristic Evaluation for Playability (HEP) [35], in addition to the set of Playability Heuristics for Mobile Games (PHMG) [32]. They found that $32 \%$ of the problems identified by HEP and $52 \%$ of the problems identified by PHMG were related to gameplay. Those problems included, for example, loss of rewards earned by players and repetitive and boring tasks.

From the literature review, one can see the importance of understanding better and of being able to evaluate gameplay so that games become more and more pleasant to be played. There are, in the literature, heuristics for gameplay evaluation. However, to date, no research results have been found that validate the use of these heuristics with games aimed at the elderly.

\section{The Current Investigation}

The results of this work were obtained from two studies. The first one focused on the evaluation, adaptation, and validation of a set of heuristics compiled from the literature. The second one aimed to develop a Grounded Theory about the desirable characteristics for the design of serious mobile games for older adults. Between the two studies, a game was developed, based on the set of heuristics proposed in the first study.

The activities that were conducted to reach the objectives of this work are presented in Figure 1. The details of these 
activities as well as the results obtained are presented in the next sections.

\section{Study 1}

The first study was organized in two phases. In the first one, gameplay evaluation heuristics were selected after a literature review [38]. Subsequently, thirty older participants interacted with a mobile casual game developed specifically for this audience and evaluated it, through a questionnaire. After the interaction, data analysis was performed and the results enabled the adaptation of gameplay heuristics to the older people [38].

In the second phase of study 1 , the adapted heuristics were validated. For this, an evaluation was performed with four older participants interacted with five selected mobile games and evaluated each of them. In addition, an evaluation by four experts was carried out, in order to verify if the results found by them were able to predict the problems and/or difficulties observed by the older adults during the evaluation process. The heuristic evaluation was performed in order to compare the results found with the evaluation with older people. All of the users had already participated in the first phase and agreed to participate in the second phase too. All the experts are participants of the Game Research Group from PUC Minas.

These evaluators applied the heuristics adapted for gameplay evaluation when they interacted with the selected mobile games. After comparing the data collected through the evaluation with older adults and the results of the evaluation by specialists, it was possible to draw up a set of heuristics which are essential for evaluation of gameplay directed to the target public of this work.

4.1. Participants. The recruitment process followed the snowball method [39], beginning with older adults known to the authors of this research.

In order to be selected, the participant should meet the following criteria: aged at least 60 years, having a basic experience in the use of cell phones, having no vision deficit that could not be corrected by corrective lenses or other disability that prevent him/her from using games on smartphones. We chose to invite only old people, and not people ageing 40 or 50 , in order to identify the impact of age in the use of mobile games. All the selected people signed the informed consent form.

Among the 30 participants of the first phase, 18 persons were women, which corresponds to $60 \%$ of participants and 12 people were men. The average age was 67 years. The youngest participant was 60 and the oldest 92 years old.

Among the four participants of the second phase, three participants were female. The mean age of the group was 64 years. The youngest was 61 years old and the oldest was 67 years old. Two adults were retired; one person was an educator and the other was a housewife. The choice of the participants took into account two variables: the experience with technology and the level of education. Two participants had a basic level of education; one of them was not familiar with the technology and the other had experience with the use of computers.

Regarding the experts, Cuperschmid and Hildebrand [40] state that an heuristic evaluation ( $\mathrm{HE}$ ) is conducted by experts based on their experience and skills. These experts examine the digital game and make a diagnosis of the problems or difficulties that users are likely to encounter during the interaction. Rocha and Baranauskas [41] state that $\mathrm{HE}$ is subjective and advise that the evaluation should be done by a group of three to five evaluators. This recommendation is due to the fact that it is difficult for a single evaluator to find all problems related to the interface. Experience shows that different people encounter different problems. Thus, we invited four specialists to participate in the HE of the games.

4.2. Materials. In the first phase of the study, we used questionnaires and a mobile game for older users "Viajando pelo Mundo". In the second phase of the study, we used questionnaires and five casual mobile games.

4.2.1. Questionnaires. Three questionnaires were developed to collect data and also the opinion and characteristics of the participants.

The first questionnaire aimed to identify the profile of the participants.

The second questionnaire was applied on the first phase after the participant interaction with the specific mobile game for older adults. It addressed characteristics of the gameplay heuristics compiled from a literature review.

The second questionnaire was developed with 18 objective questions assessed on a 5-point Likert scale and two subjective questions for the evaluation of "Viajando pelo Mundo". This questionnaire contains characteristics included in the proposed set of adapted heuristics, so that older people could reflect and comment on their perception about each heuristic: rules, clarity of objectives, tutorials, the existence of repeated and/or boring activities, fatigue and/or boredom, game progress and rewards, and positive and negative characteristics that participants identified in the game. The 18 items were statements like "The games has clear rules", "The game has boring or repetitive activities", and "The game allows the visualization of the results and players progress in the game".

The third questionnaire was applied in the second phase after the participant played each of the five selected mobile games. This questionnaire addressed the gameplay heuristics compiled from the literature review, after suiting them to the characteristics of older people.

The third questionnaire was composed of 16 items assessed on a 5-point Likert scale and two open questions. The 16 items were statements like "I understood the rules of the game", "I thought it was fun", "I liked the rewards of the game", and "I felt tired or bored". The two open questions were "What did you like the most in the game?" and "What would you change in the game?".

4.2.2. Viajando pelo Mundo. For the accomplishment of the first phase of the study, we chose a mobile game that was developed for older people. The game selected was "Viajando 
TABLE 2: Games evaluation (average scores).

\begin{tabular}{|c|c|c|c|c|c|c|}
\hline & Question & G1 & G2 & G3 & G4 & G5 \\
\hline Q1 & I understood the rules of the game. & 4.5 & 5.0 & 4.5 & 4.8 & 4.8 \\
\hline Q2 & I understood the goals of the game. & 4.8 & 4.5 & 4.5 & 5.0 & 4.8 \\
\hline Q3 & I learned from the game. & 4.5 & 5.0 & 4.3 & 5.0 & 4.5 \\
\hline Q4 & I felt a lack of help during the game. & 2.3 & 1.8 & 2.0 & 2.0 & 1.8 \\
\hline Q5 & I liked the images and the sounds of the game. & 5.0 & 4.8 & 3.8 & 4.0 & 4.8 \\
\hline Q6 & I thought it was fun. & 4.8 & 4.8 & 4.3 & 5.0 & 4.8 \\
\hline Q7 & I liked the rewards of the game. & 3.8 & 4.8 & 5.0 & 4.8 & 4.8 \\
\hline Q8 & I liked the challenges of the game. & 4.5 & 5.0 & 4.0 & 4.8 & 5.0 \\
\hline Q9 & I felt that the challenges had increased very quickly. & 2.5 & 2.8 & 3.0 & 3.0 & 2.5 \\
\hline Q10 & I felt tired or bored. & 1.3 & 1.3 & 2.3 & 2.0 & 1.3 \\
\hline Q11 & I found it easy to learn. & 4.0 & 5.0 & 4.5 & 4.5 & 4.8 \\
\hline Q12 & I followed my score in the game. & 4.5 & 4.8 & 4.5 & 5.0 & 4.8 \\
\hline Q13 & I found it interesting. & 4.8 & 5.0 & 4.0 & 4.8 & 5.0 \\
\hline Q14 & I liked the scoring system. & 3.8 & 4.8 & 4.0 & 4.5 & 5.0 \\
\hline Q15 & I found the game boring. & 1.3 & 1.0 & 2.0 & 1.0 & 1.3 \\
\hline Q16 & I feel like playing again. & 4.3 & 5.0 & 4.0 & 4.8 & 4.8 \\
\hline
\end{tabular}

G1 = aTilt 3D Labyrinth Free, G2 = Fruit Ninja Free, G3 = Find the Difference 2014 HD free, G4 = Show do Milhão 2014, and G5 = Cut the Rope: Full Free.

pelo Mundo" [42], which means "a trip around the world”, and the version used in the evaluation consisted of a trip to Brazil, France, and Japan. The game was composed of four mini-games and aimed to improve mental abilities like attention, concentration, and reasoning.

4.2.3. Mobile Games Selected. The selection of the games considered previous works that reported the factors that motivate and influence the older adults' interest in games $[43,44]$. Two of the factors are as follows: the game should be a tool to aid age restrictions and older people enjoy casual games. Thus, for the accomplishment of this study, we chose the following five mobile games:

(i) aTilt 3D Labyrinth Free: this game is based on threedimensional mazes. The player moves the cell phone to move a ball that must be placed on the target, diverting from black holes. This game exercises control and motor coordination.

(ii) Fruit Ninja Free: the goal of this game is to cut all the fruits that appear on the screen of the mobile phone by dragging the finger, simulating movements of a ninja sword. Besides motor coordination, it requires fast reasoning, lot of attention, and speed.

(iii) Find the Difference 2014 HD free: in this game the player must identify the differences between two images. To do this, one must simply click on the divergences so that they are highlighted with red circles. This game enables the improvement of abilities like attention, concentration, and reasoning.

(iv) Show do Milhão 2014: it is an interactive game of questions and answers, which provides a "prize" of up to one million reais. The questions concern several subjects that can be selected by the player. As the player evolves in the game, questions become more difficult.

(v) Cut the Rope: Full Free: the goal of this game is to cut ropes at the right time to catch stars and let a candy fall into the mouth of the monster. The game features innovative/mechanics based on physics. This game has won several awards: Apple Design Award, BAFTA Award, Pocket Gamer Award, and GDC Award e Best App Ever Award.

4.3. Results and Discussion. In the first phase, the evaluations with older adults occurred during two months.

The results of the evaluation with the game developed specifically for the older people allowed the adequacy of the heuristics compiled in the literature. This adequacy took into account all constraints, difficulties, suggestions, opinions, compliments, and observations evidenced during the evaluation process with the participants.

In the second phase, the evaluations with older adults occurred during three months.

Table 2 shows the average score of each game assigned by the participants for each of the items of gameplay evaluation. In relation to the rules and goals in the game, it can be observed that the lowest score received 4.5 points and the highest score was 5.0 points. This shows that the participants understood the purpose of each game and also the way they should interact with the games. The rewards offered in the game G3: Find the Difference 2014 HD free, pleased all participants (score of 5.0 for Q7), but did not please in the same way in the game G1: aTilt 3D Labyrinth Free, which received a score of 3.8 for the same item. Another important factor for the elderly is learning. Two games received the score of 5.0 for Q3: G2: Fruit Ninja Free and G4: Show do Milhão 2014. 
TABLE 3: Number of problems identified by experts.

\begin{tabular}{|c|c|c|c|c|c|c|c|c|c|c|c|c|c|c|c|c|}
\hline \multirow[t]{2}{*}{ Heuristics } & \multicolumn{3}{|c|}{ G1 } & \multicolumn{3}{|c|}{$\begin{array}{c}\text { G2 } \\
\text { Severity }\end{array}$} & \multicolumn{3}{|c|}{$\begin{array}{c}\text { G3 } \\
\text { Severity }\end{array}$} & \multicolumn{3}{|c|}{$\begin{array}{c}\text { G4 } \\
\text { Severity }\end{array}$} & \multicolumn{3}{|c|}{ G5 } & \multirow[t]{2}{*}{ Total } \\
\hline & $\mathbf{L}$ & M & $\mathbf{H}$ & $\mathbf{L}$ & M & $\mathbf{H}$ & $\mathbf{L}$ & $\mathbf{M}$ & $\mathbf{H}$ & L & $\mathbf{M}$ & $\mathbf{H}$ & L & $\mathbf{M}$ & $\mathbf{H}$ & \\
\hline $\mathrm{H} 1$ & & & 1 & & & 1 & & 1 & & & 1 & & & & & 4 \\
\hline $\mathrm{H} 2$ & & & & 1 & & & 1 & & & 1 & & & 1 & & & 4 \\
\hline $\mathrm{H} 3$ & & 1 & & & & 1 & & 1 & & & 1 & & 1 & & & 5 \\
\hline $\mathrm{H} 4$ & & & 1 & & & 1 & & 1 & & & 1 & & 1 & & & 5 \\
\hline H5 & 1 & & & 1 & & & 1 & & & 1 & & & & & & 4 \\
\hline H6 & & & 1 & & & & & & & & & & & & & 1 \\
\hline $\mathrm{H7}$ & & & & & & & & & & & & & & & & - \\
\hline $\mathrm{H} 8$ & & & 1 & & 1 & & & 1 & & & & & 1 & & & 4 \\
\hline H9 & & & 1 & & & 1 & & & 2 & & 1 & & & 1 & & 6 \\
\hline $\mathrm{H} 10$ & 1 & & & 1 & & & 1 & & & 1 & & & & & & 4 \\
\hline H11 & & & 1 & & & 1 & & & 2 & & 1 & & & 1 & & 6 \\
\hline H12 & 1 & & & 1 & & & 1 & & & 1 & & & 1 & & & 5 \\
\hline H13 & & & 1 & & & 1 & 1 & & & & 1 & & & & & 4 \\
\hline H14 & & & & & 1 & & & & 1 & & & & & & & 2 \\
\hline H15 & & & 1 & & & 1 & & & 1 & & & & & 1 & & 4 \\
\hline H16 & & & 1 & & & 1 & & & & & & & & & & 2 \\
\hline $\mathrm{H} 17$ & & & & & & 2 & & & & & 1 & & & & & 3 \\
\hline $\mathrm{H} 18$ & & & & 1 & & & & & & & & & & & & 1 \\
\hline H19 & & 1 & & & & & & & & & 1 & & & & & 2 \\
\hline $\mathrm{H} 20$ & & & & & & 1 & & & 1 & & & & & & & 2 \\
\hline $\mathrm{H} 21$ & & 1 & & 1 & & & 1 & & & & & & & 1 & & 4 \\
\hline $\mathrm{H} 22$ & & & & 1 & & & & & & & & & & & & 1 \\
\hline Totais & 3 & 3 & 9 & 7 & 2 & 11 & 6 & 4 & 7 & 4 & 8 & 0 & 5 & 4 & 0 & 73 \\
\hline
\end{tabular}

G1 = aTilt 3D Labyrinth Free, G2 = Fruit Ninja Free, G3 = Find the Difference 2014 HD free, G4 = Show do Milhão 2014, G5 = Cut the Rope: Full Free, L = Low, $\mathrm{M}=$ Medium, and $\mathrm{H}=\mathrm{High}$

As can be seen in Table 3, 73 problems were identified in the Expert Heuristic Assessment. The games G2: Fruit Ninja Free and G3: Find the Difference 2014 HD free were the ones that showed more problems of gameplay, being a total of 20 and 17 problems, respectively.

The results of the second evaluation with older adults and the evaluation by specialists were confronted and analysed, and then, it was possible to verify the concordant and discordant points between the two evaluations.

Table 4 shows that the second evaluation with the older adults identified 27 problems related to gameplay, representing $35.5 \%$ of the total encountered. The experts evaluation was able to find 73 gameplay problems, that is, $96 \%$ of the total. The results also show that 24 gameplay problems were detected by both older adults and experts during the evaluations.

A certain overlap of heuristics has been reported by two evaluators. In this way, one of the heuristics was discarded from the set of heuristics for gameplay evaluation.

Besidest that, after analysing the results of the evaluation of games by older adults and by experts, it was observed that some heuristics are not essential for evaluation of gameplay aimed at older adults. This is because depending on the game, the heuristics may not apply, since they are not related to all gaming genres. Thus, the validity of 21 gameplay evaluation heuristics for older adults was confirmed, with sixteen heuristics considered essential to evaluate gameplay, and five, optional.

The critical heuristics are presented in Table 5 and the optional heuristics, in Table 6.

\section{Labuta Batuta: A Game for Older Adults}

Labuta Batuta [45] is a mobile serious game for older adults, developed considering the set of heuristics proposed as a result of the first study [45]. Its name combines the word labuta, which means labor, with the old slang batuta, with similar sound, which means great, nice. The main objective of the game was to teach how to make better use of the features of a smartphone. This subject was chosen because it was a suggestion given by older people [46]. The development process lasted for about six months, with many discussion meetings.

The game allows the configuration of an avatar with the appearance of an older adult and is composed of simple mini-games that seek to teach the use of basic navigation 
TABLE 4: Number of problems identified.

\begin{tabular}{lcccc}
\hline Game & In common & Only by experts & Only by older adults & Total \\
\hline aTilt 3D Labyrinth Free & 6 & 9 & 1 & - \\
\hline Fruit Ninja Free & 6 & 14 & - & 20 \\
\hline Find the Difference 2014 HD free & 7 & 10 & 17 \\
\hline Show do Milhão 2014 & 2 & 10 & 2 & - \\
\hline Cut the Rope: Full Free & 3 & 6 & 3 & 76 \\
\hline Total & 24 & 49 & & 76 \\
\hline
\end{tabular}

TABLE 5: Critical heuristics.

CH1: The game should provide clear rules, present the main objectives at the beginning, as well as short-term goals throughout the game.

$\mathrm{CH} 2$ : The game must teach the basic skills needed at the beginning, to be used later by the players.

$\mathrm{CH} 3$ : The game should provide an interesting, engaging, and absorbing tutorial, that also simulate gameplay, allowing easy understanding.

$\mathrm{CH} 4$ : The game should use visual and audio effects to arouse interest and interaction, considering the restrictions due to ageing.

CH5: The player should find the game fun and enjoyable, without boring tasks. Repetitive tasks are acceptable as the advanced age can cause memory deficit.

CH6: The game should provide rewards which should be meaningful, enabling immersion in the game as a result of encouraging older people to play more.

CH7: The older player should not be penalized for the same error, since he/she may have attention and memory deficits. Besides that, the player should not lose any earned rewards.

CH8: Challenges should be consistent with the age restrictions of older people, providing positive experiences of the game rather than negative ones, making the player want to play more, rather than giving up.

CH9: The level of difficulty should vary so that the player experiences more challenges as the experience with the game is developed, but at a pace that does not generate frustration.

CH10: Tiredness or boredom should be minimized by varying activities and rhythm during play.

CH11: The game should be fair, engaging, easy to learn and should not be difficult to master, because the older player may have

physical or cognitive limitations.

CH12: The player must feel in control.

CH13: The gameplay should be long and enduring to keep the players' interest.

CH14: The first ten minutes of the game and the actions of the players should be obvious and should result in immediate and positive feedback for all types of players, encouraging them from the beginning of the game.

$\mathrm{CH} 15$ : The player must be able to visualize their progress in the game and also to compare the results.

CH16: The game should be fun first for the player, then for the designer.

commands on smartphones (Figure 2). The game presents the daily life of an older adult into his home using a smartphone. First, the player builds his avatar. Then, the player can navigate the rooms of the virtual house, using the smartphone to carry out various activities, such as taking pictures, sending messages, making calls, and installing and playing minigames.

Labuta Batuta offers the opportunity to learn and practice the following:

(i) Tap on the screen: at the beginning of the game, when the player needs to assemble his/her avatar choosing sex, body shape, skin tone, hair color, eye color, and clothing. It is also used in the mini-game to kill the ants. This activity is important because many old people are used to pressing buttons with force as if it was a physical button, instead of tapping lightly. (ii) Dragging objects: after creating the avatar the player can walk through the virtual house by dragging his/her finger on the screen in the chosen direction.

(iii) Taking photos, sending and receiving messages, answering and making calls, accessing the Internet, and installing games and other resources are all possibilities of learning that become available as the player progresses in the game.

The user can play six mini-games (Figure 3). In the Formiga mini-game, which means ant, the player practices tapping on the screen while "killing the ants". In the Pontos mini-game, which means points, the player learns to drag the finger on the screen while connecting the dots and forming predetermined images. In the Janela mini-game, which means window, the player will learn to use two fingers to magnify or decrease images, "opening and closing a window". 
TABLE 6: Optional heuristics.

OH1: The game must be balanced, with several ways to win.

$\mathrm{OH} 2$ : The game should provide consistency between its elements and the story.

$\mathrm{OH} 3$ : The story of the game should be part of the gameplay and should be significant, as the narrative can encourage the participation and interaction of the older player with the game.

$\mathrm{OH} 4$ : The game must have different artificial intelligence sets to provide challenges for all levels of players, whether new or experienced.

$\mathrm{OH} 5:$ The game must support a variety of paths and styles of playing.
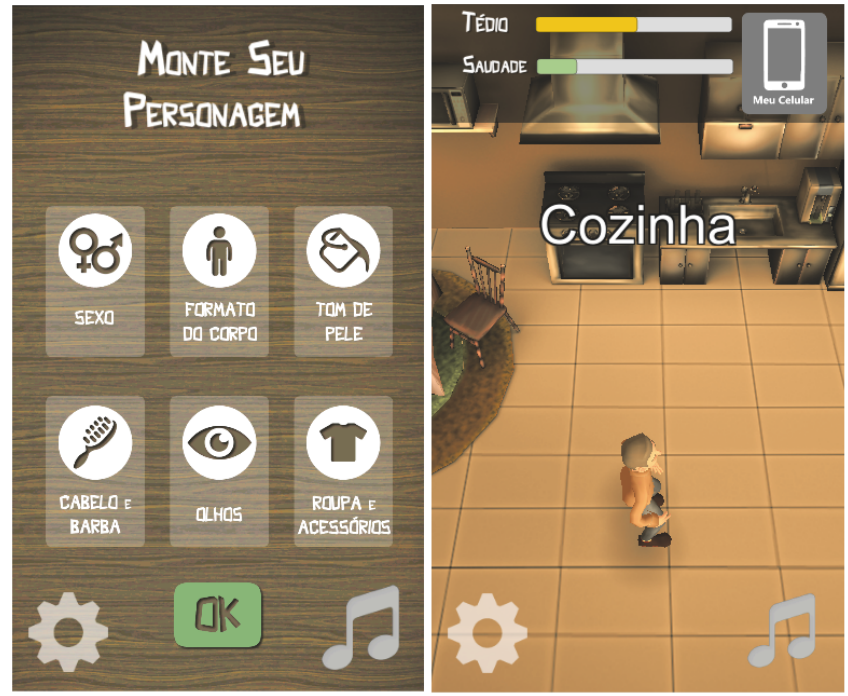
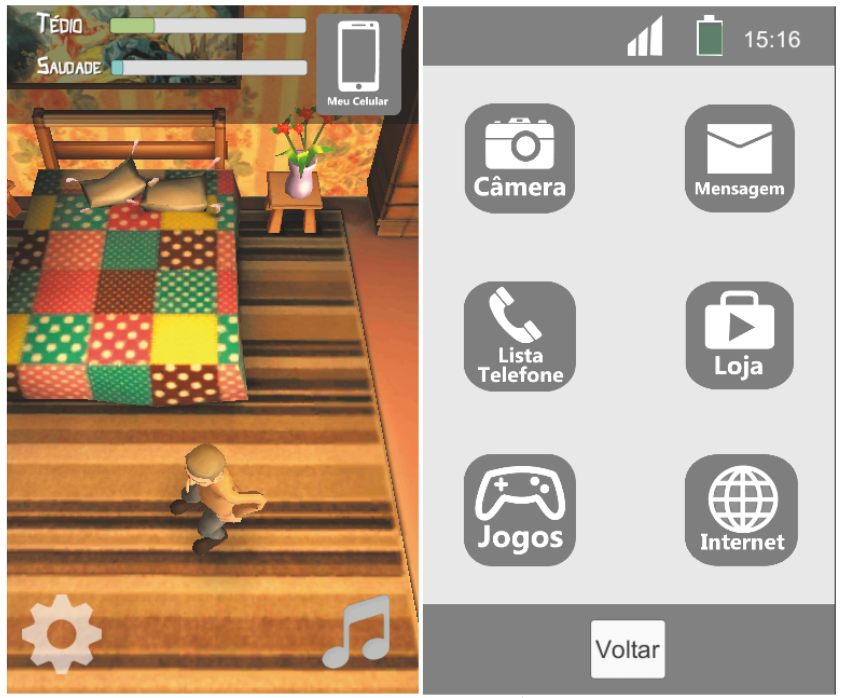

FIGURE 2: Screenshots of Labuta Batuta.

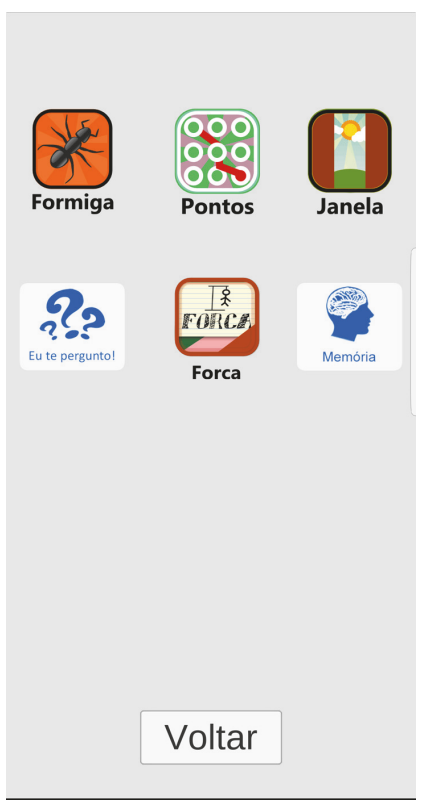

FIgUre 3: Mini-games available in Labuta Batuta.

The Memória mini-game, besides allowing the player to exercise cognitive functions such as memory and attention, also allows him/her to exercise the action of tapping the screen. The Eu te pergunto mini-game, which means "I Ask You", allows the player to learn about technical terms relating to social networking and technologies by answering a quiz. The Forca mini-game, which means gallows, uses words related to mobile phones to allow players to practice more and memorize these words.

Ferreira et al. [47] tested out the game with a group of older adults, checking if older adults would learn to use a smartphone after playing the game. The authors applied tests before and after participants played. The authors used a diary and semistructured interviews as data collection instruments and Grounded Theory for analysis. The results indicate that older adults learned to use the features of smartphone, while playing Labuta Batuta, and that they appreciate this learning option.

\section{Study 2}

The data collection took place in an environment known and chosen by the participants. In the trail test, all the participants presented a sufficient level of performance to carry out the proposed activities and to use the cell phone. The trail test was chosen because it verifies the cognitive decline and because it is of easy understanding and application for the older adults.

Next, the mobile serious game Labuta Batuta [45] was installed in the mobile phone used by the participant. Soon after, the researchers explained how to use the game and 
briefly demonstrated its functions. They also explained to participants how to fill in the diary and that they could stop participating at any time. The participants were asked to play the game every day and to fill the diary for 15 days without any intervention of the authors of this work. The time and duration of each game session were left to the participants.

After this period, the players were interviewed about the experience with the game. These interviews were recorded. Subsequently the diaries and interviews were transcribed for data analysis. The objective of using diary and interview for the data collection was to allow the methodological triangulation.

The data were analyzed using Grounded Theory and followed the guidelines proposed by [48]. The Grounded Theory seeks to meet the following criteria: have an adequate adjustment to data, utility, conceptual density, durability over time, be subject to change, and present explanatory power. In practice, development goes through four phases of data coding. Each phase must be performed judiciously since the quality of the next phase depends on the previous one and impacts on the final construction of the Theory.

In phase 1, line-by-line coding, the sentences that indicated actions and, as far as possible, the participants' words are used to create the codes. In phase 2 , focused coding, codes that direct, synthesize, and explain larger data segments, is created. In phase 3, axial coding, categories, and subcategories are developed showing the connections between them. And lastly, in phase 4, theoretical coding, we use codes created during focused coding that help us understand "how codes relate to each other as hypotheses to be integrated into a theory". Theoretical codes should be used to help clarify and stimulate the analysis, but one should avoid imposing a forced structure on the analysis [48].

6.1. Participants. For this study, new participants were selected. The criteria for the participants selection were to be at least 45 years old, to consent to voluntarily participate, to be literate, and to have no cognitive, motor, or physical impairment that would prevent the use of the cell phone. The participant did not have to own a cell phone, as the device could be lent by the research group, during the period of data collection.

As in the Study 1, the recruitment process followed the snowball method [39], beginning with older adults known to the authors of this research.

Ten older adults accepted to participate in the study. But two of the participants initially selected interrupted their participation without explanation, leaving only eight participants (six men and two women). According to Singh and Malhotra [49], this number is in agreement with the recommendation to have a minimum of eight participants using diary.

Their average age was 63 . The results from the demographic questionnaire showed that the participants had a varied level of education; most of them used cell phones daily, although they found them difficult to use; most of them did not use their cell phones to play; they would like to learn using mobile serious games. All the selected people signed the informed consent form.
A period of 15 days was established so that each participant could play and fill in the diary. This period was ideal because the chosen game does not have many features and would be repetitive if the periods were extended. In the end, the participants answered the interview questions.

It is important to highlight that the saturation of the data was perceived from the sixth participant. Besides that, Charmaz [48] states that small samples do not present a problem when using the Grounded Theory.

6.2. Materials. The instruments used in this research were a demographic questionnaire to know the profile of the participants, a trail test [50] to assess the participant's cognitive ability, and a diary for the participant's record of his/her experience while playing the game and a semistructured interview. In this study, because the game "Labuta Batuta" aimed to teach how to use the features of a mobile phone, we had to apply a trail test to find out if the participant was able to use the game and to learn.

According to Lazar et al. [51], a diary allows collecting the data over time, and the participants are responsible for choosing the places and times for the records. This makes it easier for them to record details of events as it would be harder to remember everything by the end of the data collection period. The diary needs to be well prepared to ensure a valid outcome.

The use of a diary aims to "understand the thinking processes that the gamer experiences as a human during the course of game play" [52]. This is because the players can record their impressions on the interface with more freedom.

According to [53], a diary study "minimizes the effects of observers on participants". They allow greater autonomy of the participants when registering their answers, due to the fact that the researchers are absent at the time of the events. In addition, since there is no interaction with the participant during the annotations in the diary, the participant tends to act more naturally which may allow the researcher a better perception of the events that were really important for the participants, differently from what happens when the researcher is present during the recording of the data, when the participant may feel inhibited. Besides, the use of the diary as another method of data collection allowed the comparison of the data with those collected by the interview method, configuring the methodological triangulation.

6.2.1. Development of Questions for the Diary and for the Interview. To develop the fields for the diary and the question for the final interview, we considered the six items related to game mechanics with their respective lenses [9], the 23 lenses for balancing game mechanics, and also the factors of the scale EGameFlow [29], except the social interaction factor, since the questions were directed to a single player game. To establish these correlations we observed a set of questions that are made in each of the lenses [9] and, judiciously, searched for a correlation with each of the factors of the EGameFlow scale [29]. The criterion for correlations was the use of keywords: for instance, lenses that had a question about concentration in the game were correlated to the concentration factor of the EGameFlow scale. After 
TABLE 7: An example of correlation and definition of the questions for the diary and interview.

\begin{tabular}{lccc}
\hline EGameFlow Factor & Questions for the diary & Lens number & Questions for the interview \\
\hline Concentration & 21 & 22 & $\begin{array}{c}\text { 1- What elements of the game have kept } \\
\text { your concentration on learning and } \\
\text { which hindered it. Explain. }\end{array}$ \\
& 23 & 24 & $\begin{array}{c}\text { 2- Were the game activities interesting for } \\
\text { your learning or would you like to have } \\
\text { other activities in the game? Explain. }\end{array}$ \\
\hline Feedback & Number of relationships & 4 & 28 \\
1- Explain what you think \\
of the feedback about your \\
performance during the \\
game.
\end{tabular}

this correlation, a new question was elaborated. For example, the first question of the interview has a direct link with lenses 21 and 22 which in turn has a direct correlation with the concentration factor of the EGameFlow scale. Therefore, the interview and the diary allowed approaching different factors of the scale without making the process tiring for the participants [54]. Part of this result can be seen in Table 7.

Thus, four questions were proposed for the diary and seven questions for the interview. In addition, the following criteria were used to formulate the questions: short, easyto-understand questions that do not allow only yes or no responses and a small number of questions to avoid tiring the participants.

The note fields of the diary were as follows:

(1) Explain what you think of the feedback about your performance during the game.

(2) Explain if the game's challenges were suited to your skills.

(3) Explain if you forgot the time or worries of life while playing.

(4) What did you learn?

The questions of the interview were as follows:

(1) What elements of the game have kept your concentration on learning and which hinderer it. Explain.

(2) What you did was interesting for your learning or would you like to have other actions in the game? Explain.

(3) Have the goals of the game been clearly stated? Explain.

(4) How did the game help you to overcome the challenges and how did you feel? Explain.

(5) What should a game have so that you feel in control and excited to play and learn? Explain.

(6) Were you motivated to apply what you learned in the game? Explain.
(7) What in the game called more of your attention and was it good for your learning? Explain.

6.3. Results. This section presents the main results related to study 2. The theoretical coding allowed us to specify the possible relationships among the categories developed. The relationships were generated from the answers given by the participants, in the interviews.

6.3.1. Coding of the Data Collected. 316 codes were generated in line-by-line coding, with 78 codes generated from data extracted from the diaries and 238 from the interviews.

After analysing the 316 codes generated in line-by-line coding, 81 codes were generated during focused coding. To generate the focused codes, we considered the line-by-line codes that allowed us to synthesize and explain larger data segments. In the axial coding, 15 categories were generated and for this, the most significant and/or frequent codes of the focused coding were considered. 81 subcategories were related to these 15 categories. For example, the category improvement of knowledge gather the following codes or subcategories: learning to use the touch screen, putting into practice what he/she learned through the game, considering that what he/she did in the game was interesting for his/her learning, relating game elements to day-to-day practices, relating technological terms to those presented in the game, and learning through the game.

It was observed that, of the 15 categories, six were already covered in the literature: challenges, feedback, improvement of knowledge, clear objective, immersion, and autonomy [9, 29]. The nine new categories were mini-games, performance assessment, progressing in the game, entertainment and learning, levels, use of mobile devices, concentration in learning, enjoying playing, and external links. The discovery of these nine categories reinforces the gap in the literature and causes new requirements to emerge for designing the mechanics of mobile serious games focusing on older adults.

Theoretical coding allowed us to specify the possible relationships among the categories developed. The relationships were deduced from the interviews with the participants 
TABLE 8: Theoretical codes and their relationships.

\begin{tabular}{|c|c|}
\hline Num. & Theoretical code \\
\hline 1 & $\begin{array}{c}\text { Enjoying playing affects: Improvement of knowledge, Entertainment and learning, Progressing in the game, Use } \\
\text { of mobile devices, Immersion, Performance assessment. }\end{array}$ \\
\hline 2 & $\begin{array}{c}\text { Entertainment and learning affect: Improvement of knowledge, Levels, Use of mobile devices, Enjoying playing, } \\
\text { External links. }\end{array}$ \\
\hline 3 & $\begin{array}{c}\text { Improvement of knowledge affects: Entertainment and learning, Use of mobile devices, Challenges, Levels, } \\
\text { Enjoying playing. }\end{array}$ \\
\hline 4 & Use of mobile devices affects: Entertainment and learning. \\
\hline 5 & $\begin{array}{c}\text { Clear objectives affect: Entertainment and learning, Use of mobile devices, Enjoying playing, Performance } \\
\text { assessment, Progressing in the game, External links. }\end{array}$ \\
\hline 6 & Progressing in the game affects: Enjoying playing, Improvement of knowledge, Challenges. \\
\hline 7 & $\begin{array}{c}\text { Mini-games affect: Improvement of knowledge, Use of mobile devices, Enjoying playing, Entertainment and } \\
\text { learning. }\end{array}$ \\
\hline 8 & Feedback affects: Enjoying playing e a Performance assessment. \\
\hline 9 & Levels affect: Enjoying playing, Entertainment and learning. \\
\hline 10 & Challenges affect: Improvement of knowledge, Levels, Enjoying playing \\
\hline 11 & Immersion affects: Progressing in the game, Entertainment and learning. \\
\hline 12 & Autonomy affects: Concentration in learning, Improvement of knowledge, Enjoying playing. \\
\hline 13 & Performance assessment affects: Progressing in the game. \\
\hline 14 & Concentration in learning affects: Enjoying playing. \\
\hline
\end{tabular}

[54]. The sets of theoretical codes generated are presented in Table 8.

For example, in the following statements (all names are fictitious), one can observe some of these relationships:

(i) Relationship between the categories concentration in learning and enjoying playing (code \#14):

"Ah, yes. What attracted me to games is scores, which encouraged me more and more to continue ... And the time, we do not worry about the time, in closing that game, and get more coins and more games, very good. This help us a lot to be concentrated." [Alda, P1, interview]

(ii) Relationship between improvement of knowledge and entertainment and learning (code \#3):

(...) if I need to use the Face, now I already know how to do it; and before I had difficulties, I called someone to help me, ... not now, after I learned in the game, ... I started to associate and learn, I learned better. [Arcia, P6, interview]

(iii) Relationship between clear objective and Enjoying playing (code \#5):

(...) it was all very well explained, I had no difficulty, I did not find it difficult, I thought it was cool. (...). [Equel, P3, interview]

6.3.2. Building a Grounded Theory. The relationships established and the theoretical model served as the basis for the construction of a Grounded Theory with requirements for the design of mobile serious game for older adults.
The categories enjoying playing, entertainment, and learning and improvement of knowledge are the central categories of the theoretical model because they establish the largest number of relationships and were the most affected and the ones that most affect the opinion of the players. This indicates that when older people like to play a mobile serious game they value the union of entertainment with learning and understand that this union leads to improvement of knowledge which favors immersion and continuous learning. Therefore, it is recommended that a design of the mechanics of mobile serious games for older adults considers these relationships as main requirements.

The relationships of the category use of mobile devices show that, by using a mobile device to play and learn, the older adults arouse their interest in the use of mobile technologies, which contributes to digital inclusion, entertainment, and learning of this audience.

The category clear objective and its relationships show that, by clearly understanding the goals of a mobile serious game, older adults understand better how to play. As so, they achieve the goals of the game and value the opportunity to have fun and learn at the same time, besides overcoming the barriers of using mobile technologies.

The category progressing in the game and its relationships show that as the older adult progresses in the game, he/she will becomes more interested, curious, and willing to win the game's challenges. It is worth remembering that these challenges must be appropriate to the player's abilities [28] and preferably organized in levels, because the lack of this balance can frustrate the player and stop him/her from playing.

For older adults, mini-games helped in concentration, motivated player learning, and enabled better use of the 
mobile device used to play. Therefore, the relationships of the category mini-game show another recommendation for the design of the mechanics of mobile serious games for older adults. This recommendation is to include mini-games that arouse attention and that also allow the players to evaluate their performance in the game.

The relationships of the category feedback show that feedback encourages players and influences them to enjoy the game and to continue playing, so feedback should be welldesigned and well-balanced.

Another requirement for the player to feel in control of the game is to consider his/her physical and/or cognitive limitations. An alternative is to insert external links to stimulate the older adult to exercise other movements and to learn other information.

\section{Discussion}

We identified the categories enjoying playing, entertainment, and learning and improvement of knowledge as the central categories to be considered in the design of serious game mechanics, focusing on older adults.

This indicates that when older people like to play a mobile serious game, they value the union of entertainment with learning and understand that this union leads to improvement of knowledge which favors immersion and continuous learning. Therefore, it is recommended that a design of the mechanics of mobile serious games for older adults considers these relationships as main requirements. This means that this type of game should meet requirements that allow the older adult to enjoy playing, to have fun, and mainly to improve their knowledge through play.

To meet these requirements, the game designer must consider the impairments due to ageing (Section 2.1), the set of heuristics proposed as a result of Study 1 (Section 4.3), Schell's recommendations [9], and the nine new elements that emerged from the Grounded Theory process. These nine new elements could be understood as follows:

(i) Include mini-games with educational content.

(ii) Offer frequent feedback during the game, which may also be related to the learning process.

(iii) Offer the older gamer the possibility of progressing in the game, because this progress favors the learning process.

(iv) Design an amusing game, because entertainment can lead to learning and a monotonous game can hinder learning.

(v) Include levels that allow a gradual perception of learning.

(vi) Develop games for mobile devices as they are getting increasingly used.

(vii) Avoid elements in the game that may distract the player.

(viii) Design a game that makes the older player feel good and relaxed. (ix) Present suggestions of external links with educational content.

In order to evaluate the performance and learning of the older adult through mobile educational games, we also suggest the recommendations from $\mathrm{Fu}, \mathrm{Su}$, and $\mathrm{Yu}[29]$.

\section{Conclusions}

This article presents some heuristics and recommendations for the design of mobile serious games for older adults. In the first study, a bibliographic survey was carried out to identify a set of gameplay heuristics. These heuristics were validated by a user evaluation process performed by thirty older people who interacted with a game developed exclusively for the elderly. The results of this evaluation allowed the adaptation of heuristics for evaluation of gameplay to the elderly, considering the age-related constraints.

The adapted heuristics were validated through an evaluation with four older people with a mean age of 64 years who interacted with five mobile games and an evaluation conducted by four experts. After analysing the results, the validity of 21 heuristics adapted for evaluation of gameplay for older adults was confirmed.

These heuristics can help game evaluators and game developers to identify specific gameplay problems for older adults, as they present a set of rules that aim to support the development of games for these people with quality and perspective of acceptance. The set of heuristics will also be useful for evaluating games that are not specific for the older people, and it is possible to find out if older adults will be able to interact with games developed for another age group. From these guidelines, it was possible to develop the Labuta Batuta game for the older people.

Based on Grounded Theory approach, the data analysis of the second study allowed the identification of nine important topics to be considered in game design: mini-games, performance assessment, progressing in the game, entertainment and learning, levels, use of mobile devices, concentration in learning, enjoying playing, and external links. These topics complement the ones proposed by Fu et al. [29] and Schell [9].

From the participants' point of view, the following text reinforces the importance of a mobile serious game for the older adult:
I think it ..., for me it was a great pleasure to participate ... because I have never used the Internet, to tell the truth, I have never used it, so it was a learning process for me, and I thank you for it, ... I still want a cell phone like that with more ..., more modern to use.

As future work, we suggest a study covering the heuristics that were not evaluated in this research. This includes the use of artificial intelligence to define levels of difficulties for games focusing on older people.

Future work should also include the development of a mobile serious game following the recommendations for game mechanics presented in the Grounded Theory proposed in this article. And then, test the game developed with 
older adults to validate this theory. One can also evaluate the potential of this type of game to promote the digital inclusion of the older adult.

In addition, the following research questions are suggested for future studies on mobile serious games for older adults:

(i) What topics do older adults prefer to entertain and learn while playing a mobile serious game?

(ii) How should the level design of mobile serious games for older adults be?

(iii) Which genres of games would be preferred by older adults for entertainment and learning?

\section{Data Availability}

The data used to support the findings of this study are available from the corresponding author upon request.

\section{Conflicts of Interest}

The authors declare that there are no conflicts of interest regarding the publication of this paper.

\section{Acknowledgments}

This research received financial support from PUC Minas and from CNPq [475311/2012-4].

\section{References}

[1] A. Vasconcelos, P. A. Silva, J. Caseiro, F. Nunes, and L. F. Teixeira, "Designing tablet-based games for seniors: the example of CogniPlay, a cognitive gaming platform," in Proceedings of the 4th International Conference on Fun and Games (Fn G '12), pp. 1-10, ACM, New York, NY, USA, September 2012.

[2] W. Ijsselsteijn, H. H. Nap, Y. De Kort, and K. Poels, "Digital game design for elderly users," in Proceedings of the 2007 Conference on Future Play, Future Play'07, pp. 17-22, ACM, New York, NY, USA, November 2007.

[3] A. Lopez-Martínez, S. Santiago-Ramajo, and A. Caracuel, "Game of gifts purchase: Computer-based training of executive functions for the elderly," in Proceedings of the IEEE 1st International Conference on Serious Games and Applications for Health (SeGAH '11), pp. 1-8, Braga, Portugal, November 2011.

[4] A. Ponnada and A. Kannan, "Evaluation of mobile games using playability heuristics," in Proceedings of the International Conference on Advances in Computing, Communications and Informatics (ICACCI '12), S. M. Thampi, E. El-Afry, and J. Aguiar, Eds., pp. 244-247, ACM, New York, NY, USA, 2012.

[5] M. Rice, M. Wan, M. Foo et al., "Evaluating gesture-based games with older adults on a large screen display," in Proceedings of the ACM SIGGRAPH 2011 Game Papers (SIGGRAPH '11), 8 pages, ACM, New York, NY, USA, 2011.

[6] S.-T. Chen, Y.-G. L. Huang, and I.-T. Chiang, "Using somatosensory video games to promote quality of life for the elderly with disabilities," in Proceedings of the 2012 4th IEEE International Conference on Digital Game and Intelligent Toy Enhanced Learning, DIGITEL 2012, pp. 258-262, Japan, March 2012.
[7] S. L. Chu Yew Yee, H. B. Duh, and F. Quek, "Investigating narrative in mobile games for seniors," in Proceedings of the SIGCHI Conference on Human Factors in Computing Systems (CHI '10), pp. 669-672, Atlanta, Georgia, USA, April 2010.

[8] D. Kaufman, L. Sauvé, L. Renaud, A. Sixsmith, and B. Mortenson, "Older adults' digital gameplay: patterns, benefits, and challenges," Simulation and Gaming, vol. 47, no. 4, pp. 465-489, 2016.

[9] J. Schell, The Art of Game Design: A Book of Lenses, Taylor and Francis Group, New York, NY, USA, 1st edition, 2008.

[10] A. L. Pelletier, L. Rojas-Roldan, and J. Coffin, "Vision loss in older adults," American Family Physician, vol. 94, no. 3, pp. 219226, 2016.

[11] M. Foukarakis, A. Leonidis, I. Adami, M. Antona, and C. Stephanidis, "An adaptable card game for older users," in Proceedings of the 4th International Conference on PErvasive Technologies Related to Assistive Environments (PETRA '11), 7 pages, ACM, New York, NY, USA, May 2011.

[12] J. Borg, A. Lantz, and J. Gulliksen, "Accessibility to electronic communication for people with cognitive disabilities: a systematic search and review of empirical evidence," Universal Access in the Information Society, vol. 14, no. 4, pp. 547-562, 2015.

[13] D. E. Papalia, S. W. Olds, and R. D. Feldman, Human Development, McGraw-Hill, 11th edition, 2009.

[14] S.-T. Chen, I.-T. Chiang, E. Z.-F. Liu, and M. Chang, "Effects of improvement on selective attention: Developing appropriate somatosensory video game interventions for institutionaldwelling elderly with disabilities," The Turkish Online Journal of Educational Technology, vol. 11, pp. 409-417, 2012.

[15] M. J. Rodríguez-Fórtiz, C. Rodríguez-Domínguez, and P. Cano, "Serious games for the cognitive stimulation of elderly people," in Proceedings of the 2016 IEEE International Conference on Serious Games and Applications for Health (SeGAH), pp. 1-7, Orlando, FL, USA, May 2016.

[16] H. Chi, E. Agama, and Z. G. Prodanoff, "Developing serious games to promote cognitive abilities for the elderly," in Proceedings of the 5th IEEE International Conference on Serious Games and Applications for Health, SeGAH 2017, pp. 1-8, Perth, WA, Australia, April 2017.

[17] T. T. Nguyen, D. Ishmatova, T. Tapanainen et al., "Impact of Serious Games on Health and Well-being of Elderly: A Systematic Review," in Proceedings of the 50th Hawaii International Conference on System Sciences, pp. 3695-3704, 2017.

[18] R. Nouchi, Y. Taki, H. Takeuchi et al., "Brain training game improves executive functions and processing speed in the elderly: a randomized controlled trial," PLoS ONE, vol. 7, no. 1, Article ID e29676, 2012.

[19] R. Koster, Theory of Fun for Game Design, O’Reilly, Sebastopol, CA, USA, 2nd edition, 2013.

[20] R. Savi and V. R. Ulbricht, "Jogos digitais educacionais: Benefícios e desafios," Renote, vol. 6, no. 1, 10 pages, 2008, http://seer .ufrgs.br/index.php/renote/article/view/14405/8310, Accessed on 2018-29-05.

[21] D. Michael and S. Chen, Serious games: Games That Educate, Train and Inform, Thomson, Boston, Mass, USA, 1st edition, 2006.

[22] B. Bergeron, Developing serious games (game development series), Charles Riber Media, Hingham, Mass, USA, 1st edition, 2006.

[23] R. N. S. D. Carvalho and L. Ishitani, "Motivational factors for mobile serious games for elderly users," in Proceedings of XI SBGames, pp. 19-28, 2012. 
[24] B. D. Schutter and V. V. Abeele, "Designing meaningful play within the psycho-social context of older adults," in Proceedings of the 3rd International Conference on Fun and Games, Fun and Games 2010, pp. 84-93, Belgium, September 2010.

[25] S. Pedell, J. Beh, K. Mozuna, and S. Duong, "Engaging older adults in activity group settings playing games on touch tablets," in Proceedings of the 25th Australian Computer-Human Interaction Conference: Augmentation, Application, Innovation, Collaboration (OzCHI '13), H. Shen, R. Smith, J. Paay, P. Calder, and T. Wyeld, Eds., pp. 477-480, ACM, New York, NY, USA, 2013.

[26] K. M. Gerling, F. P. Schulte, and M. Masuch, "Designing and evaluating digital games for frail elderly persons," in Proceedings of the 8th International Conference on Advances in Computer Entertainment Technology (ACE '11), 8 pages, ACM, New York, NY, USA, November 2011.

[27] G. J. Pine and P. J. Horne, The Adult Learner, Routledge, 2005, http://www.umt.edu/sell/fire/FireWeb/m410prework/The \%20Adult\%20Learner.pdf. Accessed on 2018-05-29.

[28] P. Sweetser and P. Wyeth, "Gameflow: A model for evaluating player enjoyment in games," in Computing and Entertainment, vol. 3, p. 24, 2005.

[29] F.-L. Fu, R.-C. Su, and S.-C. Yu, "Egameflow: A scale to measure learners enjoyment of e-learning games," Computers and Education, vol. 52, no. 1, pp. 101-112, 2009.

[30] V. Mello and L. Perani, "Gameplay x playability: defining concepts," in Proceedings of the SBGames, pp. 157-164, 2012, http://sbgames.org/sbgames2012/proceedings/papers/artedesign/ AD_Full20.pdf, Accessed on 2017-08-10.

[31] M. A. Federoff, "Heuristics and usability guidelines for the creation and evaluation of fun in video games," Tech. Rep., Indiana University, Bloomington, 2002.

[32] H. Korhonen and E. M. I. Koivisto, "Playability heuristics for mobile games," in Proceedings of the 8th International Conference on Human-Computer Interaction with Mobile Devices and Services (MobileHCI '06), pp. 9-16, ACM, New York, NY, USA, September 2006.

[33] R. Garris, R. Ahlers, and J. E. Driskell, "Games, motivation, and learning: a research and practice model," Simulation \& Gaming, vol. 33, no. 4, pp. 441-467, 2002.

[34] J. Nielsen, "10 usability heuristics for user interface design," https://www.nngroup.com/articles/\#popular, Accessed on 2017-06-10, 2014, 1995.

[35] H. Desurvire, M. Caplan, and J. A. Toth, "Using Heuristics to Evaluate the Playability of games," in Proceedings of the CHI '04 Extended Abstracts on Human Factors in Computing Systems (CHI EA '04), pp. 1509-1512, New York, NY, USA, April 2004.

[36] H. Desurvire and C. Wiberg, "Game usability heuristics (play) for evaluating and designing better games: The next iteration," in Proceedings of the $3 d$ International Conference on Online Communities and Social Computing: Held as Part of HCI International 2009 (OCSC '09), pp. 557-566, Springer-Verlag, Heidelberg, Berlin, 2009.

[37] H. Korhonen, J. Paavilainen, and H. Saarenpää, "Expert review method in game evaluations: comparison of two playability heuristic sets," in Proceedings of the 13th International MindTrek Conference: Everyday Life in the Ubiquitous Era (MindTrek '09), A. Lugmayr, H. Franssila, O. Sotamaa, P. Näränen, and J. Vanhala, Eds., pp. 74-81, ACM, New York, NY, USA, 2009.

[38] M. C. Machado and L. Ishitani, "Heurísticas para avaliação de gameplay direcionadas a adultos mais velhos," Revista de

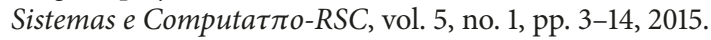

[39] P. Biernacki and D. Waldorf, "Snowball sampling: problems and techniques of chain referral sampling," Sociological Methods and Research, vol. 10, no. 2, pp. 141-163, 1981.

[40] A. R. M. Cuperschmid and H. R. Hildebrand, "Avaliação Heurística de Jogabilidade Counter-Strike: Global Offensive," in Proceedings of XII SBGames, pp. 371-378, 2013.

[41] H. V. Rocha and M. C. C. Baranauskas, Design e Avaliação de Interfaces Humano-Computador, NIED/UNICAMP, Campinas, Brazil, 2003.

[42] R. S. Silva, A. Rocha, M. S. Nery, and Á. A. Rocha, "Viajando pelo mundo: um projeto de jogo para smartphone com foco em idosos," in Proceedings of XIII SBGames, pp. 148-157, 2014.

[43] L. G. N. D. O. Santos, L. Ishitani, and C. N. Nobre, "Uso de jogos casuais em celulares por idosos: um estudo de usabilidade. uso de jogos casuais em celulares por idosos: um estudo de usabilidade," Revista de Informática Aplicada (RIA), vol. 9, no. 1, pp. 24-44, 2014.

[44] T. T. Cota, N. Vieira, and L. Ishitani, "Impacto do gênero de jogo digital na motivação dos idosos para jogar," in Proceedings of XIII SBGames, pp. 361-368, 2014.

[45] R. S. Silva, A. Rocha, M. S. Nery, and Á. A. Rocha, "Labuta batuta: um jogo educacional móvel para adultos mais velhos," in Proceedings of XIV SBGames, pp. 463-472, 2015.

[46] A. M. Mol and L. Ishitani, "Avaliação de interface de um aplicativo para uso em telefone celular e voltado para a terceira idade," in Proceedings of the IX Symposium on Human Factors in Computing Systems (IHC '10), pp. 1-10, Brazilian Computer Society, Porto Alegre, Brazil, 2010.

[47] R. L. R. Ferreira, R. B. Silva, and S. R. I. Yoshioka, "Aprendizagem do uso de smartphones por adultos mais velhos mediada por jogo educacional," in Proceedings of XIV SBGames, pp. 945954, 2015.

[48] K. Charmaz, A Construção da Teoria Fundamentada: Guia prático para análise qualitativa, Artmed, Porto Alegre, Brazil, 2009.

[49] A. Singh and S. Malhotra, "A researcher's guide to running diary studies," in Proceedings of the 11th Asia Pacific Conference on Computer Human Interaction (APCHI '13), pp. 296-300, ACM, New York, NY, USA, 2013.

[50] T. N. Tombaugh, "Trail Making test A and B: normative data stratified by age and education," Archives of Clinical Neuropsychology, vol. 19, no. 2, pp. 203-214, 2004, http://goo.gl/Qt2Twv, Accessed on 2016-03-01.

[51] J. Lazar, J. H. Feng, and H. Hochheiser, Research Methods in Human-Computer Interaction, John Wiley, Chichester, England, 2010.

[52] L. Q. En and S. S. Lan, "Social Gaming - Analysing Human Computer Interaction Using a Video-Diary Method," in Proceedings of the 2nd International Conference on Computer Engineering and Technology (ICCET), pp. 509-512, 2010.

[53] S. Carter and J. Mankoff, "When participants do the capturing: the role of media in diary studies," in Proceedings of the SIGCHI Conference on Human Factors in Computing Systems (CHI '05), pp. 899-908, USA, April 2005.

[54] L. R. R Ferreira, "Um modelo de mecânica para construção de jogos educacionais móveis para adultos mais velhos," Dissertação de mestrado Pontifícia Universidade Católica de Minas Gerais. Programa de Pós-Graduação em Informática, pp. 794-681, 2016. 


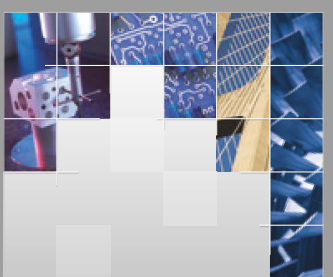

\section{Enfincering}
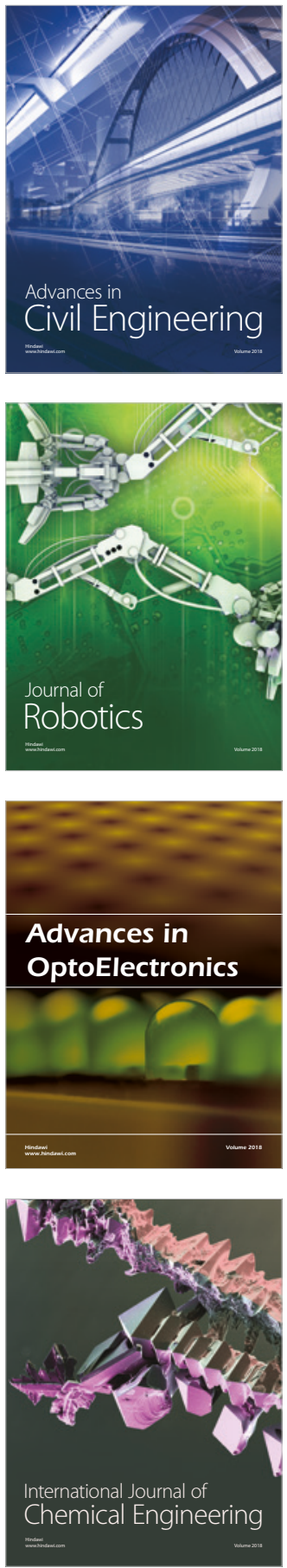

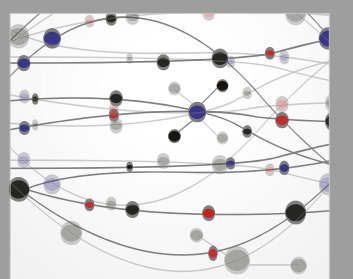

\section{Rotating \\ Machinery}

The Scientific World Journal

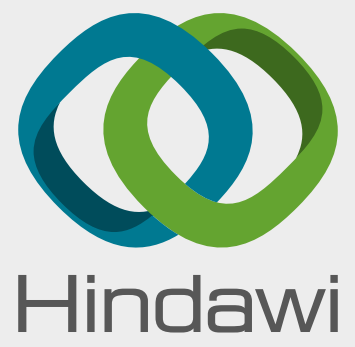

Submit your manuscripts at

www.hindawi.com
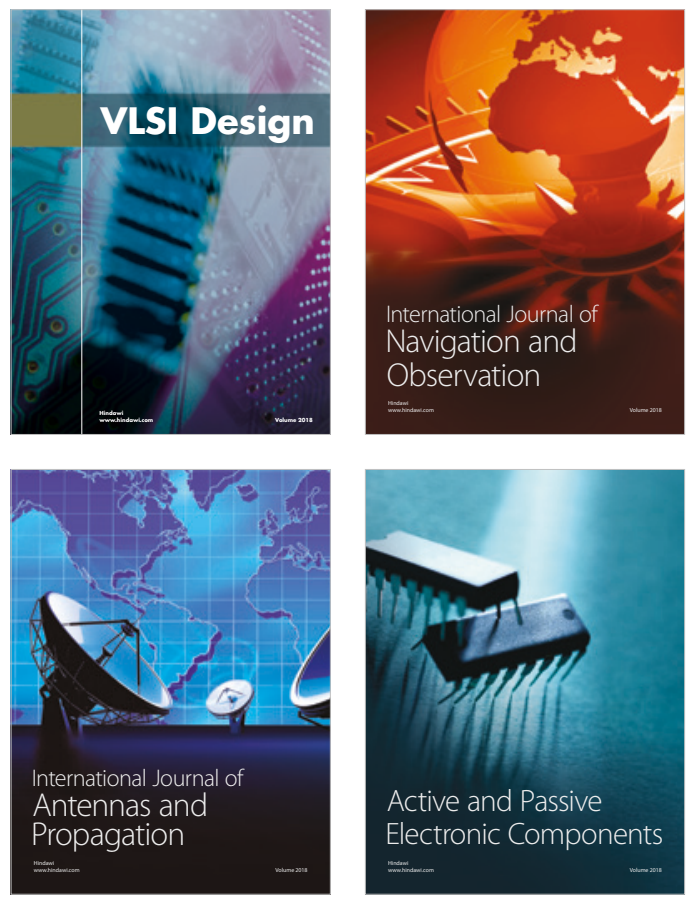
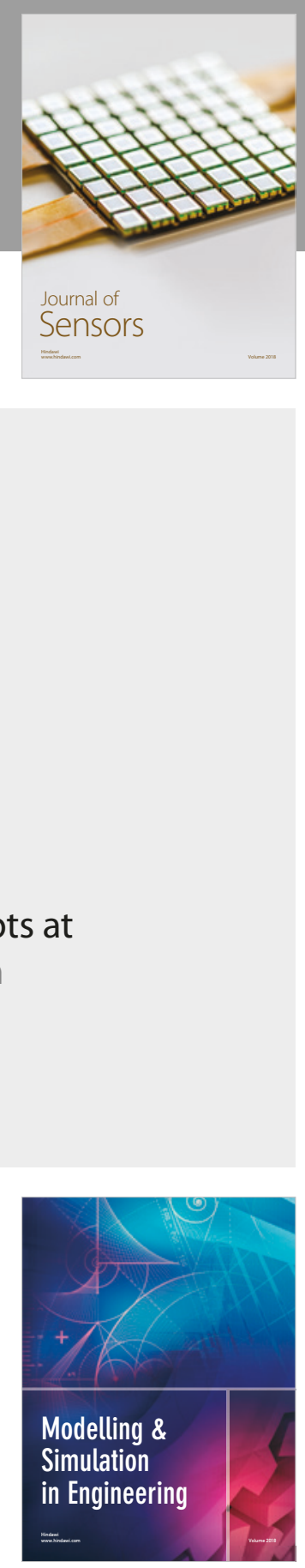

\section{Advances \\ Multimedia}
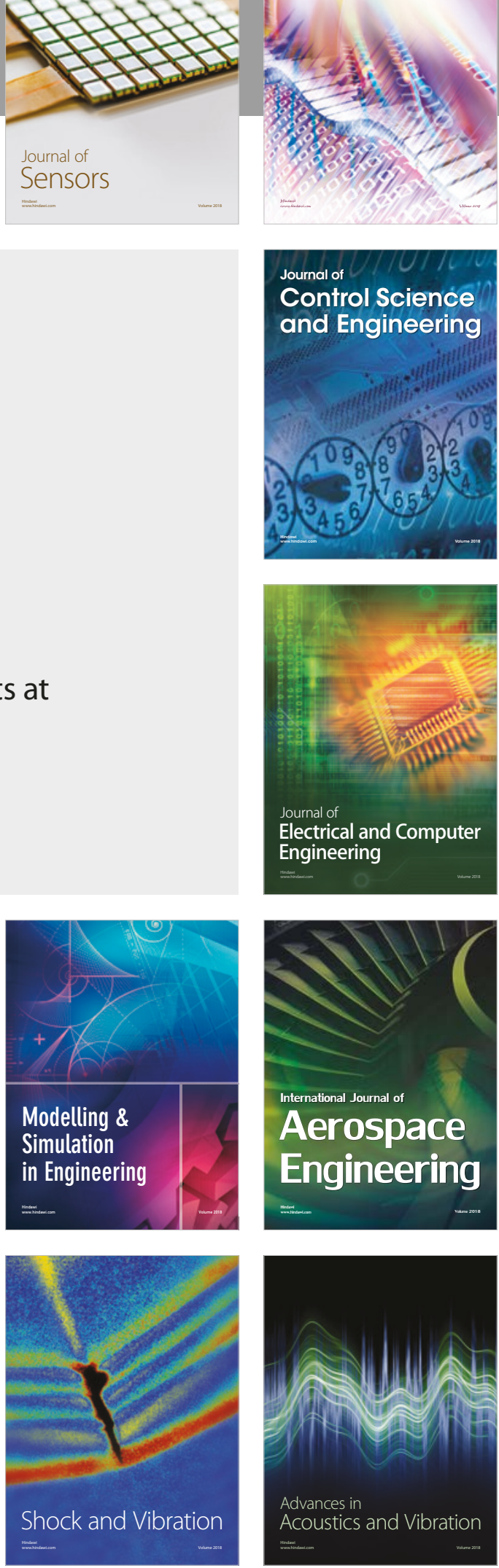